\title{
Bridging the Divide: Tensions Between the Biophysical and Social Sciences in An Interdisciplinary Sustainability Science Project
}

\author{
Susan K. Gardner ${ }^{1}$ \\ ${ }^{1}$ University of Maine, Orono, Maine, USA \\ Correspondence: Susan K. Gardner, University of Maine, 5749 Merrill Hall, Orono, ME, 04469-5749, USA. Tel: \\ 1-207-581-3122. E-mail: susan.k.gardner@maine.edu
}

\author{
Received: February 7, 2014 Accepted: March 23, 2014 Online Published: April 18, 2014 \\ doi:10.5539/enrr.v4n2p70 URL: http://dx.doi.org/10.5539/enrr.v4n2p70
}

\begin{abstract}
Interdisciplinary research has gained tremendous popularity in higher education over the past several decades and funding for such efforts through federal agencies has underscored its relevance. In sustainability science, in particular, interdisciplinarity is seen as integral to the research endeavor. However, a paucity of empirical evidence exists regarding the process of interdisciplinary endeavors, particularly those that cross the social-biophysical science divide. The current study incorporated insights over a four-year period from 25 faculty members involved in a large, interdisciplinary effort at one institution of higher education in the United States. Issues of disciplinary status, power, and hierarchy were prevalent in their accounts. Recommendations for policy and practice are included.
\end{abstract}

Keywords: interdisciplinary, collaboration, sustainability science

\section{Introduction}

Interdisciplinary research has been associated with solving urgent societal problems (Klein, 2010), but is fraught with challenges, including issues of language, culture (e.g., Quinlan \& Scogings, 2004), and the existing reward structure of higher education (e.g., American Geophysical Union, 2012). While interdisciplinary collaboration is desired it is not an easy feat; indeed, many attempts have been found to be unsuccessful (Amey \& Brown, 2004).

One relatively under-examined area related to interdisciplinary collaborations is that of disciplinary status and hierarchy. Many interdisciplinary endeavors are conducted within similar paradigmatic fields (Gardner, 2013), meaning that these disciplines will share assumptions about the nature of reality and how to observe it (Guba, 1990). Described in many different ways (Kuhn, 1962), a paradigm can be understood as "a basic set of beliefs that guides action" (Guba, 1990, p. 17). In this sense, collaborations that cross paradigmatic boundaries are inherently more difficult (Creamer, 2003), requiringfaculty to overcome not only the traditional challenges of interdisciplinary research (Holley, 2009), but also to reconcile differences in paradigmatic stances.

A paradigm can also be described as "the assumptions, practices, and agreements that guide a scholarly community" (Bess \& Dee, 2008, p. 42). As Lincoln (1985) explained, paradigms reflect world views and are shaped by a set of beliefs. Indeed, paradigms guide choices research topics, theoretical perspectives, methodological approaches, and even decision-making (Bess \& Dee, 2008). Paradigms are also associated with particular academic disciplines (Biglan, 1973b). For example, the natural sciences may be associated with a paradigmatic stance that sees the world as primarily positivistic, meaning that there is one (and only one) "reality," that is independent of any one person's perspective (Guba, 1990). Positivists may be seen as seeking to find and accurately describe external reality - such as through the scientific method. Many social sciences, however, are associated with various paradigms, wherein there is a more "soft" orientation toward paradigmatic stances rather than a "hard" or immutable view toward reality (Biglan, 1973b) - hence giving rise to the hard/soft distinction among disciplines (Biglan, 1973a).

Therefore, when one chooses to cross paradigmatic lines - perhaps a social scientist working with a biophysical scientist, for example - complications can be inherent. Kuhn (1962) even went so far as to argue that different paradigmatic views of research could be incommensurable. Burrell and Morgan (1979) further explained, "One cannot operate in more than one paradigm at any given point in time, since in accepting the assumptions of one, we defy the assumptions of all the others" (p. 25). Nevertheless, this is precisely what interdisciplinary research 
often attempts to do: cross paradigmatic boundaries; particularly when such interdisciplinary collaboration involves researchers from disciplines from the biophysical and social sciences.

These two areas of academia, the biophysical and social sciences, have a history of operating relatively in isolation from one another. This is not to say, however, that both areas have not had a rich history of interdisciplinarity; indeed, many of today's scientific and social breakthroughs have been heralded as a product of such disciplinary border-crossing (Klein, 2010). At the same time, these border-crossing efforts have generally occurred within paradigmatic lines - wherein the social sciences have often worked with other social scientists (geology and anthropology, e.g.) or the biophysical sciences with others in similar paradigmatic fields (biology and chemistry, e.g.). Such paradigmatic-crossing collaborative efforts have been found to be inherently more difficult (Creamer, 2003), due to the many challenges described above.

In this study, I examined the experiences of 25 faculty members from the biophysical and social sciencesinvolved in one interdisciplinary project over a four-year period to examine their experiences of crossing paradigmatic lines. I begin with an overview of the literature related to interdisciplinary collaborations, followed with the methods used to conduct the study. The findings are then presented as well as a discussion of their implications for policy, practice, and future research.

\section{Interdisciplinary Collaborations Across Paradigms}

Interdisciplinary research can be defined as "a mode of research by teams or individuals that integrates information, data, techniques, tools, perspectives, concepts, and/or theories from two or more disciplines or bodies of specialized knowledge to advance fundamental understanding or to solve problems whose solutions are beyond the scope of a single discipline or area of research practice" (National Academy of Sciences, National Academy of Engineering, \& Institute of Medicine, 2005, p. 26). Due to the complexity and challenges involved (Klein, 1990, 2005), tensions within interdisciplinary teams are inherent.Indeed, the literature about interdisciplinary research and collaboration is rife with these challenges, including issues related to crossing disciplinary boundaries, language, time, and structural issues (e.g., Holley, 2009; Klein, 1990; Lattuca, 2001; Jacobs, 2013).

Disciplines are both organizational and social structures within academia (Becher \& Trowler, 2001). Disciplines represent specialized cultures, made up of their own habits, practices, value systems (Clark, 1987), and status hierarchies (Becher, 1981). As such, when differing disciplines meet to collaborate, participants must bridge both the traditional interdisciplinary challenges, such as those described above, as well asthe social hierarchies that exist. Klein (Klein, 1990) remarked, "Interdisciplinary teams ... are status systems that reflect external hierarchies and disciplinary chauvinism" (p. 127). In turn, many interdisciplinary collaborations may find one discipline in service to another, or what Miller et al. (2008) described as "epistemological sovereignty" (p. 8). For example, interdisciplinary endeavors that cross the hard and soft divide may often group together social sciences in a service role to a biophysical science(MacMynowski, 2007).

The concept of a "hard" versus a "soft" science rests mainly in the different paradigmatic stances that are represented. Biglan (1973a) pointed out that fields with a single paradigm ("hard") will have a greater consensus than those without ("soft"). For example, a discipline such as biology and its scientists will tend to utilize one paradigm that is reflected in its methods and conceptualizations of science (i.e., the scientific method), whereas a more low-consensus discipline, such as communications, might engender several paradigmatic stances wherein multiple methods and methodologies are commonplace to capture the different perspectives that exist.

Given these differences, it is not surprising that differences in paradigmatic stances have engendered status conflicts, and even some negativity, such as through the pejorative use of the terms "hard" and "soft" (Guba, 1990; Hedges, 1987). Heretofore, this paper references "high consensus" versus "low consensus" disciplines to better distinguish these differences and avoid such exacerbating language.

Becher and Trowler (2001) further refined Biglan's (1973a, 1973b) work to distinguish between high consensus-low consensus disciplinesand pure-applied disciplines, wherein pure disciplines tend to value the research done "for research sake" versus applied disciplines that value a practical or utilitarian view of their research. Table 1 provides an overview of Becher and Trowler's grouping of academic disciplines. 
Table 1. Becher and Trowler's disciplinary grouping

\begin{tabular}{|c|c|}
\hline Disciplinary Groupings & Nature of Knowledge \\
\hline $\begin{array}{l}\text { Pure sciences (e.g., } \\
\text { biophysical sciences) } \\
\text { High Consensus-Pure }\end{array}$ & $\begin{array}{l}\text { Cumulative; atomistic; concerned with universals, quantities, } \\
\text { simplification; impersonal, value-free; clear criteria for knowledge } \\
\text { verification and obsolescence; consensus over significant questions to } \\
\text { address, now and in the future; results in discovery/explanation }\end{array}$ \\
\hline $\begin{array}{l}\text { Humanities (e.g., history) } \\
\text { and Pure social sciences } \\
\text { (e.g., anthropology) } \\
\text { Low Consensus-Pure }\end{array}$ & $\begin{array}{l}\text { Reiterative; holistic; concerned with particulars, qualities, complication; } \\
\text { personal, value-laden; dispute over criteria for knowledge verification and } \\
\text { obsolescence; lack of consensus over significant questions to address; } \\
\text { results in understanding/ interpretation }\end{array}$ \\
\hline $\begin{array}{l}\text { Technologies (e.g., } \\
\text { engineering) } \\
\text { High Consensus-Applied }\end{array}$ & $\begin{array}{l}\text { Purposive; pragmatic; concerned with mastery of physical environment; } \\
\text { applies heuristic approaches; criteria for judgment are purposive, } \\
\text { functional; results in products/techniques }\end{array}$ \\
\hline $\begin{array}{l}\text { Applied social science } \\
\text { (e.g., education) } \\
\text { Low Consensus-Applied }\end{array}$ & $\begin{array}{l}\text { Functional; utilitarian; concerned with enhancement of professional } \\
\text { practice; uses case studies; results in protocols/procedures }\end{array}$ \\
\hline
\end{tabular}

Beyond paradigmatic differences, these varying stances toward the ultimate use of the research - pure versus applied - can also create tensions in collaborative efforts. Feibleman (1961) described pure or basic research as being concerned with "the need to know", whereas applied science is tasked with the use of science "for some practical human purpose" (p. 305). While a simple definition, Feibleman's conceptualization does point to potential challenges inherent when working across this divide. For example, among some scholars, there is perceived to be a relative status or hierarchy to conducting one kind of research over another. Feibleman himself remarked,

[Applied sciences] are conducted by men [sic] whose chief desires are practical: either the improvement of human conditions or profit, or both. Temperamentally, the applied scientists are not the same as the pure scientists: their sights while valid are lower; they are apt to be men of greater skill but of lesser imagination (p. 309).

In this way, a social hierarchy or status between the pure/applied divide becomes salient among those who perceive one kind of research as more important or worthy than another. Indeed, even the term "pure" could imply "that applied research is somehow tainted" (Pielke \& Byerly, 1998, p. 43).

These social divides between and among different disciplines, therefore, have larger implications for potential interdisciplinary collaborations. Like any other social organization, academic disciplines reflect inherent power differentials (Becher \& Trowler, 2001; Clark, 1987) and dynamics that may affect their interactions. Bernstein (1971) was noted as saying that a discipline's classification and its framing essentially reflect power relationships. Clark (1987) even went so far as to name the power and status some disciplines had over others. Other markers of status and hierarchy can also been seen in other areas, such as academic budgets (Huber, 1990) and even the gender balance represented in the discipline, with more "feminized" disciplines generally regarded as less prestigious and even earning less than their more male-dominated counterparts (Bellas, 1997; Kulis, Sicotte, \& Collins, 2002).

Despite the importance of these social differences between disciplines and paradigms, relatively little empirical work exists about such issues in interdisciplinary collaborations, instead relying on anecdote to make such claims. Moreover, while a plethora of scholarship and commentary exists about the challenges of conducting interdisciplinary research (e.g., American Geophysical Union, 2012; Amey \& Brown, 2004; Derry \& Schunn, 2005; Golde \& Gallagher, 1999; Wear, 1999), relatively little has examined specific challenges within particular disciplinary groups rather than monolithically.

\section{Methods}

Lattuca (2001) pointed out, "It is fruitless to talk about the process of doing interdisciplinary work without discussing the influence of the contexts in which it is done" (p. 20). As such, the guiding research question for this study was, "What are the experiences of faculty working across paradigmatic lines in an interdisciplinary 
research collaboration at one institution?" The study was best suited as a qualitative case study in that it was a "detailed examination of one setting" (Bogdan \& Biklen, 2003, p. 54), or a mid-sized, research university in which the project was situated. Specifically, the project was a $\$ 20$ million, five-year, federally funded project focused on sustainability, spanning over 25 distinct disciplines, including those primarily from the social sciences and the biophysical sciences. In this way, the project under investigation became a fascinating case study as it, by design, spanned the multiple paradigms of these different disciplinary groups.

The label of biophysical sciences was one that wasintroduced by the participants. While classified in many ways, depending on the context, in the SP, the biophysical sciences were any disciplines that were "other than" the social sciences. In the SP context, therefore, this included the disciplines of ecology, forestry, marine sciences, and even engineering. In this same perspective, the social sciences were conceptualized by the participants as anything "other than" STEM-related fields (or those in the sciences, technology, engineering, or mathematics), which one might traditionally view as those such as psychology, sociology, anthropology, and economics.

Qualitative methods were chosen for this study as they allowed for an understanding of the meaning, for the participants in the study, of the events, situations, and actions they are involved with and the accounts they give of their experiences; the particular context within which the participants act and the influence the context has on their actions; and the process by which events and actions take place (Maxwell, 1996, pp. 17-19).

In Year 1, the leadership team of the project, hereafter referred to as the Sustainability Project (SP), was approached and asked to identify individual faculty members who had been integrally involved in SP's success to that point. From the list of 42 faculty affiliated with SP, 29 faculty members were identified - including the majority of proposal authors. These 29 individuals were contacted via e-mail to seek their participation with 25 finally agreeing to be interviewed in Years 1-4 of the SP. The 25 faculty members included faculty from all ranks and diverse disciplines, including 13 men, 12 women, and 2 faculty of color. The faculty interviewed had been at the institution for an average of 9.82 years, with 16 individuals holding tenured positions. Using Becher and Trowler's (2001) disciplinary grouping, a total of 8 individuals represented the high-pure paradigm; 5 from the low-pure; 4 from the high-applied; and 7 from the low-applied (see Table 2).

Table 2. Study participants by Becher and Trowler's disciplinary grouping

\begin{tabular}{ll}
\hline Becher \& Trowler's Disciplinary Groupings & Study Participants by Discipline \\
\hline & Wetland ecology (1) \\
& Earth sciences (1) \\
Pure sciences (e.g., biophysical sciences) & Biogeochemistry (2) \\
High-Pure & Marine sciences (1) \\
& Limnology (1) \\
& Wildlife ecology (1) \\
& Conservation biology (1) \\
Humanities (e.g., history) and & Communication (1) \\
Pure social sciences (e.g., anthropology) & Social psychology (2) \\
Low-Pure & Anthropology (1) \\
\hline Technologies (e.g., engineering) & Human ecology (1) \\
High-Applied & Environmental engineering (1) \\
\hline Applied social science (e.g., education) & Civil engineering (1) \\
Low-Applied & Forest resources and policy (2) \\
\hline
\end{tabular}

After obtaining consent, interviews with the 25 individuals took place in face-to-face settings. The interviews lasted 30 to 120 minutes in each year, were audio-taped, and then transcribed verbatim. Transcripts were analyzed using the constant comparative method (Glaser, 1978) and guided by the theoretical framework 
provided by Becher and Trowler (2001) in relation to paradigmatic stances. In particular, this study utilized Glaser's (1978) steps in data analysis, wherein first open-coding was utilized to understand the larger dynamics at work in the faculty perceptions of the interdisciplinary collaboration, resulting in a set of themes. Then, further coding was utilized to make explicit the connections between the themes that emerged and corresponded with the existing literature on interdisciplinarity (e.g., Holley, 2009; Klein, 1990, 2010; Lattuca, 2001; Repko, 2008). Finally, a third round of coding allowed for a search of concepts that tied into the emic themes (Strauss \& Corbin, 1998) that emerged from the participants' interviews.

Trustworthiness of the data collected and subsequent analysis was obtained through peer debriefing (Maxwell, 1996), wherein another colleague was given access to transcripts for their analysis and verification of themes;member checking, wherein faculty were asked to review the themes that emerged from their interviews; as well as through triangulation of data sources (Bogdan \& Biklen, 2003; Maxwell, 1996) as the current study was a part of a larger study in which multiple administrators, faculty, and students were interviewed.

\section{Findings}

Presented below are the findings related to the 25 faculty members' experiences bridging the divide between paradigmatic stances over a four-year period. First, I begin with an overview of the SP so as to provide context for the study and its setting. Then, I discuss the longitudinal experiences of faculty in their bridging of paradigms.

\subsection{The Scope of the Sustainability Project (SP)}

The SP was a five-year long, $\$ 20$ million project focused on sustainability. By its nature, the project was focused on applied science, with its goal to provide data-driven policies and decisions in the public realm toward a sustainable future. Like other interdisciplinary research problems (Holley, 2009; Klein, 1990, 2010; Lattuca, 2001; Repko, 2008), sustainability is one that requires broad-ranging perspectives and therefore requires knowledge from multiple disciplinary arenas (Clark, Kates, \& Members of the Board on Sustainable Development of the National Research Council, 1999; Kates et al., 2001). A law professor involved in the SP underscored this point, saying, "The mission of the project as a whole is really, really quite ambitious. I don't see how you get at that without contributions from multiple disciplines."

Consequently, the fact that over 25 disciplines were involved in the SP was no accident. Instead, the principal investigator (PI) of the project shared his desire to bring together individuals to work on this issue throughout his long career but was unable to muster enough enthusiasm at his previous institution, where basic science was the considered the currency of the realm. He discussed what he called his "coming out process" regarding his desire to engage in applied research: "[At one point] I decided I'm coming out of the closet, and I'm going togive a seminar and it's going to be called 'Why Practice Applied Ecology' ... none of the faculty showed up for my seminar." As he continued to learn more about the issues surrounding applied research, he also learned more about the ways in which to inform it. He said, "I started to try to understand how other fields would fit into this and as I did that I just became aware or how many different ways of knowing there are." It was through this process, and coming to a land-grant institution where this kind of research could be valued, that the SP was born.

And, while every faculty member interviewed for this study stated that they had experience with what they classified as interdisciplinary collaboration in the past, all were also adamant in pointing out the unique nature of the SP. One of the economists remarked, "I have not attempted something this big. I have never worked at this scale, with this many people, on this complex of an issue."

The faculty members emphasized other unique characteristics of this project and its scope, with many attributing the SP's existence to an institutional culture that would allow for such an endeavor to occur. Some faculty attributed this willing culture to a relatively small campus, while others attributed the public institution's dwindling state coffers to its willingness to experiment and take risks. A communication faculty member explained her perspective:

I think [it works at this institution] partly because it's just not organized at all, really. Do you know what I mean? It doesn't map on to any other university I've ever been involved with in terms the colleges and schools. It's just easier to do interdisciplinary research here probably than many other places simply because there isn't a real pattern to disciplinarity here that you have in a lot of other places.

Similarly, a low-applied faculty member shared:

It's an academic institution: it's got silos, it's got traditions. That makes it cumbersome and awkward and risky. On the other hand, [this institution] is small and it's got a tradition of informal interdisciplinary connections because it's small. I think the university seems quite interested in anything that is going to help 
it stand out, help it collect research money, help it be cutting edge, help it be working for the state's future, which I see the SP very much is doing. So, institutionally, you know, there is some openness on the part of the higher-ups.

Another unique aspect of the SP merits explanation: once the \$20M was awarded to the institution, the PIs collectively decided on a portfolio approach. In other words, faculty members were allowed to pick a specific sustainability-focused issue and assemble a team at that time to address it. What this meant was that research questions, methods, and procedures were not decided in advance but rather emerged as time passed. Moreover, it was expected that these individual teams include at least two disciplines - with a special emphasis on the joining together of social scientists and biophysical scientists, in particular. Indeed, more funding was granted to the teams that had the most interdisciplinary connections. In this way, studying the SPlongitudinally allowed for an understanding of how these individual interdisciplinary teams - all unique in their own right - came to learn to do interdisciplinary work and to cross the disciplinary and paradigmatic boundaries that existed.

\subsection{Bridging the Paradigms}

Therefore, interviewing these 25 faculty members each year at the same time allowed for a developmental view of the interdisciplinary collaboration process - something discussed by authors such as Amey and Brown (2004). What was evidenced, interestingly, was the changing landscape of faculty members' perceptions of interdisciplinarity, particularly in those collaborations that crossed paradigmatic lines.

For example, in the early months of Year 1, while manyfaculty expressed optimism at the potential collaborations underway, a number of the faculty began to express some concerns about collaborations across the high-low consensus divide. Perhaps interesting in and of itself was the fact that the participants began to refer to themselves as belonging to one of two groups: the biophysical scientists (or, all STEM-related disciplines) or the social scientists. From early on, therefore, they began to draw this division amongst themselves. A social scientist remarked, "I think a lot of times the assumption out there is that the social scientists should learn this and the biophysical scientists arejust going to keep doing what they're doing." A faculty member in the low-applied area also shared, "I'm interested to see how the social science piece of the project winds up working with the science piece. Those seem to be fairly different disciplinary traditions. I'm wondering how that interaction will work out."

It was, therefore, the social scientists more than the biophysical scientists who expressed repeatedly in Year 1 their concerns about the high-low consensus divide. In fact, social scientists in Year 1 talked about their responsibility in having to bridge the high-low divide; that it required less ego and more flexibility than perhaps the biophysical scientists were capable of. A social scientist said, "Actually, in some ways, the social scientists have to have even an even higher dose of humility in this and say, 'I'm willing to work a little harder and a little extra to make this work." Whereas other social scientists felt they were in a more supportive role to the "science" being done: "I feel like the majority of the SP work is going to be done by the natural scientists, honestly. I feel like I am in more of a supportive role." In turn, a biophysical scientist explained, "Along with one of the ecologists in the group, we sort of felt like we were supposed to define the problem and then the others [the social scientists] would build off of that somehow. That's just an impression I guess we have."

By Year 2, as the faculty began working together more and presenting their research to one another, conflicts and misunderstandings began to emerge. A high-consensus scientist remarked, "At the risk of being too forthright, I think that a lot of the biophysical types feel that the social science types are pretty squishy: Where are the hypotheses? Where are the statistics?" In turn, an interesting shift began to occur in Year 2: it was the biophysical scientists who began to express discontent and uncertainty about their status in the project. One such high-pure scientist said, "I guess when I look at the model that has developed in the project, in many ways this is more about the social sciences. I see less and less appeal all the time." Another high-pure scientist remarked, "I have some difficulty seeing the value that some of the social sciences have. I've sat through a number of the lectures that some of the social science people have given and walked away wondering what the point was." As such, some of the biophysical scientists felt their needs weren't being met. One explained, "I think there's a fundamental conflict here in the way people get things done. Maybe the biophysical people are sort of dropping out or becoming less interested because they don't get as much out of the process [as the social scientists]."

By Year 3, the biophysical-social science scale had resoundingly tipped in the high-consensus scientists' eyes. Many such faculty expressed concerns of being "outnumbered" by social scientists while social scientists expressed concerns about not feeling respected by the biophysical scientists. Many biophysical scientists began to be concerned about what they perceived as attrition of the high-consensus scientists from the SP. Interestingly, these concerns emerged from both sides. A social scientist remarked, "There are more resources 
going to the social and behavioral science projects, which could be problematic for [the biophysical] people." Another social scientist expressed his concerns, "If the biophysical becomes the helpmeet to the social science, I think that will become really stressful for the biophysical researchers because they see their knowledge produced as driving the change." It was not surprising to hear from social scientists, then, that "social scientists look at interdisciplinarity a lot more positively than biophysical scientists."

Even into Year 4 the divide continued as a source of concern for many and frustration for others. A biophysical scientist explained, "From the biophysical perspective is just the feeling that there should have been 50/50 and now it appears to be more social science than biophysical," and another stated, "I guess I had my own kind of selfish interests that [the SP] was going to be about physical science-type things coupled with social science. I don't think that has happened. In fact, I'd say the biophysical side has been greatly downplayed." Yet another stated, "Some of the biophysical researchers sort of feel like that the people who are flourishing in SP seem to be the social scientists, while the biophysical scientists still have to do our same old stuff in order to contribute. There's sort of a feeling that traditional biophysical research is not being appreciated."

\section{Discussion}

Interdisciplinarity is recognized as an inherent need for solving the world's most pressing problems (National Academy of Sciences et al., 2005; National Science Foundation, 2009). At the same time, conducting interdisciplinary research is by no means easy. In this study, a particular challenge was highlighted: that of the differences in status and power between different paradigmatic fields and the resulting tensions in one interdisciplinary endeavor.

In the interdisciplinary project examined, representation, resources, knowledge claims, and status provided sources of tension between the biophysical and social scientists. While the SP was designed to provide an avenue for both sides to come together to solve larger sustainability problems, it was apparent that the "divide," as it was so often called by the faculty, was not easily overcome. On one hand, it seemed the faculty were ready to create this divide themselves, by calling themselves either a biophysical scientist or a social scientist, and readily creating a dichotomy between two poles, seemingly. No one crossed those lines or ever identified as someone who was outside this dichotomous divide. At the same time, the issues and struggles that the literature related to interdisciplinarity has well documented worked to reinforce this divide. For example, biophysical scientists expressed a lack of appreciation or respect for the methods and methodologies used by social scientists. Moreover, while the emphasis (and power) seemed to be placed on the biophysical sciences in the first year of the SP, this scale appeared to be tipped to the social sciences by the second year and beyond - at least according to the participants. Interestingly, however, no actual records exist to substantiate that any more resources were distributed or any more faculty were represented on one side or the other.

These issues of imbalance and what at times appeared to be concerns about status and power support the conceptual understandings of epistemological sovereignty provided by Miller et al. (2008). In the SP, the early months showed an expectation of the social scientists serving in the helping role to biophysical scientists - a point shared by both sides. As the project progressed, however, the biophysical scientists saw this trend shift and were concerned about their service roles to the social scientists. At no time, however, did any social scientists express concerns about such a position.

The disciplinary classifications forwarded by Biglan (1973) and Becher and Trowler (2001) also were prevalent in the findings. For example, the divisions created by methods and paradigmatic stances were apparent in not only how the biophysical scientists saw themselves but also how they saw their social science counterparts. The lack of paradigmatic consensus apparent in the social sciences was of concern to many of the high-pure scientists, making them question the value of their contributions. It was perhaps only the economists that seemed to escape some of the negative light cast on the other social scientists by the biophysical faculty. One may suspect that the placement of economics on both Biglan's and Becher and Trowler's classifications as a more high-consensus discipline may have smoothed their relationships with the other high consensus disciplines.

In concordance with MacMynowski (2007), issues of hierarchy and power were prevalent among social scientists and biophysical scientists. Indeed, concerns of attrition among biophysical scientists on the SP were prevalent in Years 2 through 4. When prompted about why such attrition occurred, it often had to do with these issues in power imbalance or loss of status. Also interesting to observe was the sea change from Year 1 to Year 4 in these perspectives. It was common to hear social scientists in Year 1 saying they were uncertain about their contributions to SSI. In Year 3 and 4, it was the biophysical scientists who expressed this uncertainty - often to the point of not feeling valued or needed any longer. 
Recommendations for policy, practice, and future research can be drawn from these findings. First, interdisciplinary endeavors that seek to cross such paradigmatic divides should be mindful about the difficulties in doing so and purposeful in providing opportunities to cross them. While more recent scholars have worked to "defend the disciplines" (Jacobs, 2013) or even point to the already porous nature of many disciplinary endeavors (Abbott, 2001), the fact remains that interdisciplinarity does not readily occur in most research institutions due to these difficulties and challenges (Amey \& Brown, 2004). Through structured conversations about the contributions of both sides, workshops about methodologies, reading groups, and even co-teaching and co-advising students, faculty from different paradigmatic stances may be brought together to better understand each other's perspectives. These efforts should be conducted not only early in the collaboration, but throughout it, to ensure ongoing and deepening understandings over time. These opportunities can be tailored around selected readings that address these challenges as well as seminars related to methods, underlying assumptions, and how paradigms influence these outcomes. Second, institutions can provide the resources to support the infrastructure for these efforts, such as through course releases, summer stipends, and the like. The time needed to support interdisciplinary work cannot be underestimated and, to do it well, it may not be accomplished "on top of" other typical duties and responsibilities. Third, it was apparent in the SP that such divides take years to overcome. Only in Year 4, and only in some cases, did a few of the individual teams express feeling they had gotten to a place of integration and connection among the disciplines. Being mindful about timelines in relation to grant-funded interdisciplinary projects would be helpful to accomplish research goals, given the cultural and paradigmatic divides that such researchers may need to overcome.

While this study examined only one project at one institution, future studies should consider the interplay of disciplines and institutional context to determine the best predictors of paradigm-crossing collaborations. Which social sciences and biophysical sciences may find work together easiest? Similarly, understanding the typology and background characteristics of those more well-suited to this kind of collaboration may also prove fruitful in the quest to tackle today's most pressing problems through interdisciplinary research.

\section{Acknowledgements}

Supported by National Science Foundation award EPS-0904155.

\section{References}

Abbott, A. (2001). Chaos of disciplines. Chicago, IL: University of Chicago Press. http://dx.doi.org/10.1063/1.1398543

American Geophysical Union. (2012). Is pretenure interdisciplinary research a career risk? Eos, 93(32), 311-312. http://dx.doi.org/10.1029/2012EO320004

Amey, M. J., \& Brown, D. F. (2004). Breaking out of the box: Interdisciplinary collaboration and faculty work. Greenwich, CT: Information Age.

Becher, T. (1981). Towards a definition of disciplinary cultures. Studies in Higher Education, 6, 109-122. http://dx.doi.org/10.1080/03075078112331379362

Becher, T., \& Trowler, P. R. (2001). Academic tribes and territories (2nd ed.). Philadelphia, PA: Open University Press.

Bellas, M. L. (1997). Disciplinary differences in faculty salaries: Does gender bias play a role? Journal of Higher Education, 68, 299-321. http://dx.doi.org/10.2307/2960043

Bernstein, B. (1971). On the classification and framing of educational knowledge. In M. F. D. Young (Ed.), Knowledge and control (pp. 47-69). London, UK: Collier Macmillan.

Bess, J. L., \& Dee, J. R. (2008). Understanding college and university organization: Theories for effective policy and practice. Sterling, VA: Stylus.

Biglan, A. (1973a). The characteristics of subject matter in different academic areas. Journal of Applied Psychology, 57, 195-203. http://dx.doi.org/10.1037/h0034701

Biglan, A. (1973b). Relationships between subject matter characteristics and the structure and output of university departments. Journal of Applied Psychology, 57, 204-213. http://dx.doi.org/10.1037/h0034699

Bogdan, R. C., \& Biklen, S. K. (2003). Qualitative research for education: An introduction to theories and methods. Boston: Allyn and Bacon.

Burrell, G., \& Morgan, G. (1979). Sociological paradigms and organizational analysis. London, UK: Heinemann. 
Clark, B. R. (1987). The academic life: Small worlds, different worlds. Princeton, NJ: Carnegie Foundation.

Clark, W. C., Kates, R. W., \& Members of the Board on Sustainable Development of the National Research Council. (1999). Our common journey: A transition toward sustainability. Washington, DC: National Academy Press.

Creamer, E. G. (2003). Exploring the link between inquiry paradigm and the process of collaboration. The Review of Higher Education, 26, 447-465. http://dx.doi.org/10.1353/rhe.2003.0012

Derry, S. J., \& Schunn, C. D. (2005). Interdisciplinarity: A beautiful but dangerous beast. In S. J. Derry, C. D. Schunn \& M. A. Gernsbacher (Eds.), Interdisciplinary collaboration: An emerging cognitive science (pp. xiii-xx). Mahwah, NJ: Lawrence Erlbaum Associates.

Dressel, P. L., \& Marcus, D. (1982). On teaching and learning in college. San Francisco, CA: Jossey-Bass.

Feibleman, J. K. (1961). Pure science, applied science, technology, engineering: An attempt at definitions. Technology and Culture, 2, 305-317. http://dx.doi.org/10.2307/3100886

Gardner, S. K. (2013). Paradigmatic differences, power, and status: A qualitative investigation of faculty in one interdisciplinary research collaboration on sustainability science. Sustainability Science, 8, 241-252. http://dx.doi.org/10.1007/s11625-012-0182-4

Glaser, B. (1978). Theoretical sensitivity: Advances in the methodology of grounded theory. Mill Valley, CA: Sociology Press.

Golde, C. M., \& Gallagher, H. A. (1999). The challenges of conducting interdisciplinary research in traditional doctoral programs. Ecosystems, 2, 281-285. http://dx.doi.org/10.1007/s100219900076

Guba, E. C. (1990). The alternative paradigm dialog. In E. C. Guba (Ed.), The paradigm dialog (pp. 17-27). Newbury Park, CA: Sage.

Hedges, L. V. (1987). How hard is hard science, how soft is soft science? The empirical cumulativeness of research. American Psychologist, 42, 443-455. http://dx.doi.org/10.1037/0003-066X.42.5.443

Holley, K. (2009). Understanding interdisciplinary challenges and opportunities in higher education. San Francisco: Jossey-Bass.

Huber, L. (1990). Disciplinary cultures and social reproduction. European Journal of Education, 25, 241-261. http://dx.doi.org/10.2307/1503315

Jacobs, J. A. (2013). In defense of disciplines: Interdisciplinarity and specialization in the research university. Chicago, IL: University of Chicago Press. http://dx.doi.org/10.7208/chicago/9780226069463.001.0001

Kates, R. W., Clark, W. C., Corell, R., Hall, J. M., Jaeger, C. C., Lowe, I., ... Svedlin, U. (2001). Sustainability science. Science, 292, 641-642. http://dx.doi.org/10.1126/science.1059386

Klein, J. T. (1990). Interdisciplinarity: History, theory, and practice. Detroit, MI: Wayne State University.

Klein, J. T. (2005). Interdisciplinary teamwork: The dynamics of collaboration and integration. In S. J. Derry, C. D. Schunn \& M. A. Gernsbacher (Eds.), Interdisciplinary collaboration: An emerging cognitive science (pp. xiii-xx). Mahwah, NJ: Lawrence Erlbaum Associates.

Klein, J. T. (2010). Creating interdisciplinary campus cultures. San Francisco, CA: Jossey-Bass.

Kuhn, T. S. (1962). The structure of scientific revolutions. Chicago, IL: University of Chicago Press.

Kulis, S., Sicotte, D., \& Collins, S. (2002). More than a pipeline problem: Labor supply constraints and gender stratification across academic science disciplines. Research in Higher Education, 43, 657-691. http://dx.doi.org/10.1023/A:1020988531713

Lattuca, L. R. (2001). Creating interdisciplinarity: Interdisciplinary research and teaching among college and university faculty. Nashville, TN: Vanderbilt University Press.

Lincoln, Y. S., \& Guba, E. G. (1985). Naturalistic inquiry. Newbury Park, CA: Sage.

MacMynowski, D. P. (2007). Pausing at the brink of interdisciplinarity: Power and knowledge at the meeting of social and biophysical science. Ecology and Society, 12, 20-33.

Maxwell, J. A. (1996). Qualitative research design: An interactive approach. Thousand Oaks, CA: Sage.

Miller, T. R., Baird, T. D., Littlefield, C. M., Kofinas, G., Chapin, F. S., \& Redman, C. L. (2008). Epistemological pluralism: Reorganizing interdisciplinary research. Ecology and Society, 13(2), 46-62. 
National Academy of Sciences, National Academy of Engineering, \& Institute of Medicine. (2005). Facilitating interdisciplinary research. Washington, DC: National Academies Press.

National Science Foundation. (2009). Interdisciplinary research. Retrieved December 8, 2009, from http://www.nsf.gov/funding/pgm_summ.jsp?pims_id=503439\&org=NSF\&sel_org=NSF\&from=fund

Pielke, R. A., \& Byerly, R. (1998). Beyond basic and applied. Physics Today, 51(2), 42-46. http://dx.doi.org/10.1063/1.882141

Quinlan, T., \& Scogings, P. (2004). Why bio-physical and social scientists can speak the same language when addressing Sustainable Development. Environmental Science \& Policy, 7, 537-546. http://dx.doi.org/10.1016/j.envsci.2004.08.006

Repko, A. F. (2008). Interdisciplinary research: Process and theory. Thousand Oaks, CA: Sage.

Rossini, F. A., Porter, A. L., Kelly, P., \& Chubin, D. E. (1979). Frameworks and factors affecting integration within technology assessments. In R. Barth \& R. Steck (Eds.), Interdisciplinary research groups: Their management and organization (pp. 161-196). Seattle, WA: Interstudy.

Strauss, A., \& Corbin, J. (1998). Basics of qualitative research: Techniques and procedures for developing grounded theory (2nd ed.). Thousand Oaks, CA: Sage.

Wear, D. N. (1999). Challenges to interdisciplinary discourse. Ecosystems, 2, 299-301. http://dx.doi.org/10.1007/s100219900080

\section{Copyrights}

Copyright for this article is retained by the author(s), with first publication rights granted to the journal.

This is an open-access article distributed under the terms and conditions of the Creative Commons Attribution license (http://creativecommons.org/licenses/by/3.0/). 